\title{
Females Have a Lower Liver Histopathological Score in HBeAg-Negative Chronic Hepatitis B Than Males
}

\author{
Afshin Hooshyar ${ }^{1}$; Shahram Habibzadeh ${ }^{2, *}$; Nasrin Ghasemi ${ }^{3}$; Abbas Yazdanbod ${ }^{1}$; Sirus \\ Sohrabi ${ }^{4}$; Nasrollah Maleki ${ }^{3}$; Firooz Amani ${ }^{5}$ \\ ${ }^{1}$ Department of Gastroenterology, Imam Khomeini Hospital, Ardabil University of Medical Sciences, Ardabil, IR Iran \\ 2 Department of Infectious Disease, Imam Khomeini Hospital, Ardabil University of Medical sciences, Ardabil, IR Iran \\ ${ }^{3}$ Department of Internal Medicine, Imam Khomeini Hospital, Ardabil University of Medical Sciences, Ardabil, IR Iran \\ ${ }_{5}^{4}$ Department of Emergency medicine, Shahid Beheshti University of Medical sciences, Tehran, IR Iran \\ ${ }^{5}$ Department of Emergency medicine, Shahid Beheshti University of Medical sciences, Te \\ ${ }^{*}$ Corresponding author: Shahram Habibzadeh, Department of Infectious Disease, Imam Khomeini Hospital, Ardabil University of Medical sciences, Ardabil, IR Iran. Tel: +98- \\ 9144519670, Fax:+98-4515510057, E-mail: s.habibzadeh@arums.ac.ir
}

Received: March 3, 2013; Revised: May 22, 2013; Accepted: August 5, 2013

\begin{abstract}
Background: More than 350 million people are chronic carriers of hepatitis B virus(HBV)and because of the high HBV-related morbidity and mortality, the global disease burden of HBV is substantial. In patients with HBeAg-negative chronic hepatitis B (CHB) with serum alanine aminotransferase (ALT) levels, 1-2 $\times$ upper limit of normal (ULN) and HBV DNA load of 10000 to 100000 copies/mL, liver biopsy should be considered and treatment may be initiated if liver biopsy shows moderate/severe necro-inflammation or significant fibrosis. A dynamic balance between viral replication and host immune response is pivotal for the pathogenesis of liver disease in HBV infection. Due to immune response variability, there is thought to be a considerable difference in the histopathologic status of liver biopsy samples present in various populations.

Objectives: Liver histopathology in asymptomatic patients with greater than 10000 DNA copies/mL despite negative Hbe Ag was studied to determine, the number of people that will benefit from a liver biopsy, and variables that will significantly be affected by viral load changes.

Patients and Methods: Eighty-two symptomless hepatitis B patients, identified during screening tests, were entered into the study. All candidates were HBS Ag Positive, Hbe Ag negative, Hbe Ab positive, HDV Ab, HIV Ab 1, 2, and HCV Ab negative. In all cases HBV DNA virus load was greater than 10000 copies $/ \mathrm{mL}(2000 \mathrm{U} / \mathrm{mL})$. Liver biopsy was done after obtaining a written consent. Liver histopathology was reported based on the histological activity index (HAI).

Results: Both HBV DNA load and serum ALT levels significantly correlated with the grade score. Both stage and grade significantly correlated with age. Stage score of liver specimens was significantly lower in women than men. Logistic regression analysis indicated that the baseline ALT and HBV DNA levels and age were independent predictors of the HAI score.

Conclusions: In 10\% of the patients, liver biopsy changed the treatment plan and treatment was started despite ALT levels being less than twice the normal level.
\end{abstract}

Keywords:Hepatitis B Virus; Pathology; Chronic

\section{Background}

Hepatitis B virus (HBV) is a serious public health problem worldwide. More than 350 million people are chronic carriers of HBV and because of high HBV-related morbidity and mortality, the global disease burden of HBV is substantial (1). In China, for example, Hepatitis B imposes a considerable economic burden on a family as the sum of direct medical and nonmedical costs, ranging from $30.72 \%$ (for acute hepatitis B) to $297.85 \%$ (for primary liver cancer) of the average annual household income (2). The prevalence of chronic HBV infection varies geographically, from high (>8\%) to intermediate $(2-7 \%)$ and low $(<2 \%)$ prevalence. The Islamic Republic of Iran is a country in which hepatitis $B$ prevalence is at the intermediate level (3). In the Ardabil province HBsAg positive prevalence rate among blood donors has been $1.4 \%$ (4).

A dynamic balance between viral replication and host immune response is pivotal to the pathogenesis of liver disease in HBV infection (5). Furthermore, environmental factors like alcohol consumption, and viral factors including genotype of the virus and presence of mutations in core and precore promoters may affect the viral load $(6,7)$. In HBeAg-negative patients, it is difficult to define

Implication for health policy/practice/research/medical education:

In patients with asymptomatic chronic hepatitis B, liver biopsy may change the therapeutic options in some of them, and there are some predictor factors for liver pathologic score.

Copyright (C) 2013, Infectious Diseases and Tropical Medicine Research Center. This is an open-access article distributed under the terms of the Creative Commons Attribution License, which permits unrestricted use, distribution, and reproduction in any medium, provided the original work is properly cited. 
a single cutoff HBV DNA value for differentiating inactive carriers from patients with HBeAg-negative chronic hepatitis (6), thus liver biopsy has been used as a last resort. In patients with $\mathrm{HBeAg}$-negative $\mathrm{CHB}$, treatment should be considered if ALT is $>2 \times$ ULN and HBV DNA is $>2000$ $\mathrm{IU} / \mathrm{mL}$. If ALT is $1-2 \times$ ULN and DNA is $2000-20000 \mathrm{IU} / \mathrm{mL}$, liver biopsy should be considered and treatment may be initiated if liver biopsy shows moderate/severe necro-inflammation or significant fibrosis (8).

\section{Objectives}

Due to immune response variability, there is thought to be a considerable difference in the histopathologic status of liver biopsy samples present in various populations. Thus, the present study evaluated liver histopathological status of patients with high DNA copy loads in their serum despite negative $\mathrm{HbeAg}$, to determine the number of people that will benefit from a liver biopsy and the variables that are significantly affected by viral load changes.

\section{Patients and Methods}

During a one-year period in a cross sectional study, all symptomless hepatitis B patients, identified during screening tests (for blood donation, pregnancy, surgery, etc) were evaluated. All of the following, HBsAg, HbeAg, Hbe Ab, HIV Ab 1, 2, and HCV Ab were checked. HBV DNA virus load was checked in our hospital's genetic laboratory. All of the HBsAg Positive patients with negative HbeAg (positive Hbe Ab), negative HDV Ab, negative HIV $\mathrm{Ab} 1,2$ and negative HCV Ab, provided that they had a HBV DNA virus load greater than 10000 copies/mL (2000 U/ $\mathrm{mL}$ ), were entered in the study. According to routine recommendations in management of chronic hepatitis B, liver biopsy was done for all candidates after obtaining a written consent. All of the specimens, were histopathologically examined by one expert pathologist, based on Histological Activity Index (HAI) (9).

Sonographic examination of the liver was done to rule out cirrhosis and biopsy contraindication. Exclusion criteria for patients in this study were; alcoholism, history of antiviral therapy in the past, simultaneous infection with HIV or HCV. DNA viral load was measured quantitatively using the Primer Design ${ }^{\mathrm{TM}}$ genesig Kit for Hepatitis B Virus (HBV) Genomes with 100\% homology in a broad range of clinically relevant reference sequences, and high priming efficiency of $>95 \%$ to detect less than 100 copies of the target template.

Antibody detection was done using the Chemiluminescence technique. All of the collected data were saved confidentially and analyzed via the SPSS software (version 16) using the chi-square and independent samples t-tests and the linear regression model. P values less than 0.05 were considered statistically significant.

\section{Results}

Eighty-two patients were evaluated during this study with a mean age of $35.01 \pm 11.7$ years (19-77) and 47 being male (57.3\%) and 35 female (42.7\%). The mean amount for serum ALT level and HBV-DNA copies per mL (Multiply in 10000) were $65.23 \pm 20.13 \mathrm{U} / \mathrm{mL}$ (11-147) and 6523.44 \pm 34387.37 copies/mL, respectively. History of chronic hepatitis $B$ in at least one other family member in 35 patients $(42.7 \%)$ and carrier state in mother in $8 \%(9.8 \%)$ of patients were positive. Others had no information about hepatitis B status of their family. At the time of diagnosis, all of the patients were clinically asymptomatic. Histopathological report of liver biopsies was provided based on the Knodell Score. Mean \pm SD for grade and stage of HAI were $4.4 \pm 3.3$ and $0.44 \pm 0.81$, respectively. To detect the relationship between the two variables, linear regression was used. A linear regression line is described by the following equation; $\mathrm{Y}=\mathrm{a}+\mathrm{bX}$, where $\mathrm{X}$ is the explanatory variable and $\mathrm{Y}$ is the dependent variable. The slope of the line is $\mathrm{b}$, and $\mathrm{a}$, is the intercept (the value of $\mathrm{y}$ when $\mathrm{x}=0$ ). $P$ value $<0.05$ means $95 \%$ Confidence interval for $b$, does not include 0 .

Among variables, both HBV DNA load and serum ALT levels significantly correlated with grade of HAI. Both stage and grade significantly correlated with age, but Pvalue for stage was more significant (Table 1). Among patients with less than twice the normal levels of ALT, consisting of 42 males (51.2\%) and 29 females (35.3\%), liver biopsy results were interesting and about $15 \%$ of men and $7 \%$ of women needed treatment (Tables $2-5$ ). Another interesting finding of the study was the significant difference in the liver stage index of liver biopsies between men and women. Despite the absence of a significant mean difference in viral DNA load, serum ALT and age among the two sexes $(\mathrm{P}=$ $0.127, \mathrm{P}=0.22$ and $\mathrm{P}=0.96$ respectively, $\mathrm{t}$ test), stage scores in liver specimen biopsies were significantly lower in women than men and stages greater than score 1 were not seen in women. Difference in histopathological status of the liver among sexes was limited to stages and statistical differences were not seen in grade or total HAI. Chi-square test values for determination of significant differences in histological status including stage, grade and total HAI among sexes were $0.024,0.485$, and 0.228 , respectively.

Logistic regression analysis indicated that the baseline ALT, HBV DNA levels and age were independent predictors of the HAI score. To describe the relationship between the three explanatory variables (age, ALT and HBV DNA load) and the response variable (HAI) multiple linear regression was used and a regression equation with a relatively low R-Squared (0.20) was obtained (if R-Squared = 1.0, then given the value of one term, one can perfectly predict the value of another term and if R-Squared $=0.0$, then knowing one term does not help with determining the other term). 
Hooshyar A et al.

$\mathrm{HAI}=-0.455+0.72 \log (\mathrm{HBV}$ DNA/10000 $)+0.075($ Age $)+$ 0.029 (ALT)

This means that in asymptomatic CHB patients with greater than 10000/mL HBV DNA copies/mL, every 10000 copies increase in HBVDNA load, or 10 years increase in age, and/or $25 \mathrm{U} / \mathrm{mL}$ increase in serum ALT level, can rise HAI by 0.7. For example in a 50-year-old man with serum $\mathrm{ALT}=70$ and HBV DNA level $=10^{8}$, HAI is expected to be equal to 5 .

Table 1. Relationship Between the Three Explanatory Variables a

\begin{tabular}{lccccc}
\hline $\begin{array}{l}\text { Dependent Vari- } \\
\text { able: } \mathbf{Y}\end{array}$ & $\begin{array}{c}\text { Explanatory Vari- } \\
\text { able: } \mathbf{X}\end{array}$ & \multicolumn{2}{c}{ Unstandardized Coefficients } & Correlation Coef- & P Value \\
\cline { 3 - 4 } ficient: $\boldsymbol{\rho}$ & \\
\hline Grade score & $\log (\mathrm{HBV} / 10000)$ & 0.7 & 2.8 & 0.35 & 0.001 \\
Grade score & ALT & 0.02 & 2.9 & 0.31 & 0.004 \\
Stage score & Age & 0.01 & -0.19 & 0.25 & 0.02 \\
Grade score & Age & 0.5 & 2.2 & 0.22 & 0.04 \\
HAI & Age & 0.07 & 2.04 & 0.24 & 0.02 \\
\hline
\end{tabular}

a Abbreviations: ALT, alanine aminotransferase; HAI, histological activity index.

Table 2. HAI Stage Score for Men With ALT Levels Less Than Twice the Normal Level

\begin{tabular}{lccc}
\hline Stage score & Frequency & Valid Percentage & Cumulative Percentage \\
\hline $\mathbf{0}$ & 34 & 81.0 & 81.0 \\
$\mathbf{1}$ & 5 & 11.9 & 92.9 \\
$\mathbf{3}$ & 2 & 4.8 & 97.6 \\
$\mathbf{5}$ & 1 & 2.4 & 100.0 \\
Total & 42 & 100.0 & \\
\hline
\end{tabular}

Table 3. HAI Grade Score for Men With ALT Levels Less Than Twice the Normal Level

\begin{tabular}{lccc}
\hline Grade score & Frequency & Valid Percentage & Cumulative Percentage \\
\hline $\mathbf{1}$ & 7 & 16.7 & 16.7 \\
$\mathbf{2}$ & 8 & 19.0 & 35.7 \\
$\mathbf{3}$ & 8 & 19.0 & 54.8 \\
$\mathbf{4}$ & 6 & 14.3 & 69.0 \\
$\mathbf{5}$ & 3 & 7.1 & 76.2 \\
$\mathbf{6}$ & 4 & 9.5 & 85.7 \\
$\mathbf{7}$ & 1 & 2.4 & 88.1 \\
$\mathbf{8}$ & 2 & 4.8 & 92.9 \\
$\mathbf{1 0}$ & 2 & 4.8 & 97.6 \\
$\mathbf{1 2}$ & 1 & 2.4 & 100.0 \\
\hline
\end{tabular}

Table 4. HAI Stage Score for Women With ALT Levels Less Than Twice the Normal Level

\begin{tabular}{lccc}
\hline Stage score & Frequency & Valid Percentage & Cumulative Percentage \\
\hline $\mathbf{0}$ & 16 & 55.2 & 55.2 \\
$\mathbf{1}$ & 13 & 44.8 & 100.0 \\
Total & 29 & 100.0 & \\
\hline
\end{tabular}

Table 5. HAI Grade Score for Women With ALT Levels Less Than Twice the Normal Level

\begin{tabular}{lccc}
\hline Grade Score & Frequency & Valid Percentage & Cumulative Percentage \\
\hline $\mathbf{0}$ & 1 & 3.4 & 3.4 \\
$\mathbf{1}$ & 5 & 17.2 & 20.7 \\
$\mathbf{2}$ & 7 & 24.1 & 44.8 \\
$\mathbf{3}$ & 2 & 6.9 & 51.7 \\
$\mathbf{4}$ & 1 & 3.4 & 55.2 \\
$\mathbf{5}$ & 5 & 17.2 & 72.4 \\
$\mathbf{6}$ & 6 & 20.7 & 93.1 \\
$\mathbf{7}$ & 1 & 3.4 & 96.6 \\
$\mathbf{9}$ & 1 & 3.4 & 100.0 \\
\hline
\end{tabular}




\section{Discussion}

In the present study both HBV DNA load and serum ALT levels significantly correlated with grade of HAI (but not with stage). Both stage and grade significantly correlated with age. HAI stages in liver specimen biopsies were significantly lower in women than men and stages greater than one were not seen in women. Logistic regression analysis indicated that the baseline ALT and HBV DNA levels and age were independent predictors of the HAI score.

In the present study, both HBV DNA load and serum ALT levels significantly correlated with grade of HAI (but not with stage). Correlation between ALT and HAI has been evaluated previously by some other studies in Iran. In a cross-sectional study of $146 \mathrm{CHB}$ patients, by Babamahmoodi et al. 94 were HBeAg negative and 52 were HBeAg positive and there was a significant relationship between HBV-DNA level and ALT enzyme (10). Review of 86 hepatic biopsies by Semnani et al. also showed a significant relationship between AST, ALT serum levels and Knodell HAI quantitative scores $(P<0.05)$ (11). Using summative methodology, statistically significant and consistent correlations between viral load level or change and histological grading and biochemical and serologic response were shown in 26 prospective studies (12). Viraemia levels also reflect the clinical stages of chronic hepatitis B virus (HBV) infection, in 'healthy carriers'. Increasing HBV DNA level was associated with significantly higher inflammation and fibrosis in HAI scores and higher ALT (ALT / the upper reference value) (13).

In the present study, both stage and grade significantly correlated with age. HAI stages in liver specimen biopsies were significantly lower in women than men. In a cohort of 70 Caucasian patients with chronic hepatitis B, older age, male sex, cirrhosis at entry and absence of sustained remission predicted liver-related death, independently. The risk of liver-related mortality in Caucasian adults with chronic hepatitis B is strongly related to sustained disease activity and ongoing high level of HBV replication independent of HBeAg status (14).

Normal ALT itself is not a reliable marker for taking the right decision and liver biopsy can detect a considerable number of patients who need treatment (15). Kumar et al. showed that in HBeAg negative patients with chronic HBV infection with persistently normal ALT, $13 \%$ have fibrosis stage $\geq 2$ and a fair proportion of such subjects have significant liver damage. They also declared that $35.3 \%$ of HBeAg-negative cases that were incidentally detected as asymptomatic HBsAg-positive patients with persistently normal ALT, had baseline HBV DNA levels $\geq$ 5-log copies/mL; 39.7\% had HAI > 3; and 13.8\% had fibrosis stage $\geq 2$ on histology (16). Thus, a cutoff point for HBV DNA load for anticipating probable liver damage in CHB patients has been suggested. In the present study, by considering a cut-off point of seven for grade and two for stage as a treatment onset point for patients with ALT levels less than twice the normal level, about 15\% of men and $7 \%$ of women needed to be treated. Higher HAI stage in men in comparison with women may be due to some other virulence factors such as diet, job, hormonal effects, drug consumption and etc.

Overall, at least in 10\% of these patients, liver biopsy changed treatment options and treatment was initiated despite ALT levels being less than twice the normal level. In our HBeAg-negative $\mathrm{CHB}$ patients with greater than 10000 copies/mL HBV DNA, male sex, higher age, higher viral load and higher ALT significantly correlated with HAI. HAI stages in liver specimen biopsies were significantly lower in women than men.

\section{Acknowledgements}

This study was prepared from the postgraduate thesis of Dr. Nasrin Ghasemi. The authors thank Dr. Said Hosseini Asl, Reza Didevar, Parva Mokhallegh Sani, and Hamid Gharehasanlou for performing the quantitative PCR, liver biopsy report and liver biopsy, respectively.

\section{Authors' Contributions}

Study concept and design: Shahram Habibzadeh and Afshin Hooshyar; acquisition of data: Shahram Habibzadeh and Afshin Hooshyar; analysis and interpretation of data: Abass Yazdanbod; drafting of the manuscript: Shahram Habibzadeh; critical revision of the manuscript for important intellectual content: Nasrollah Maleki; Statistical analysis: Firooz Amani and Sirus Sohrabi; administrative, technical, and material support: Nasrollah Maleki and Nasrin Ghasemi; study supervision: Afshin Hooshyar and Shahram Habibzadeh.

\section{Financial Disclosure}

There were no financial interests related to the materials in this manuscript.

\section{Funding/Support}

This study was prepared from the postgraduate thesis of Dr. Nasrin Ghasemi, and supported by the deputy of Research and Technology of Ardabil Medical University of Sciences.

\section{References}

1. Hou J, Liu Z, Gu F. Epidemiology and Prevention of Hepatitis B Virus Infection. Int J Med Sci. 2005;2(1):50-7.

2. Lu J, Xu A, Wang J, Zhang L, Song L, Li R, et al. Direct economic burden of hepatitis $B$ virus related diseases: evidence from Shandong, China. BMC Health Serv Res.;13:37.

3. Poorolajal J, Majdzadeh R. Prevalence of chronic hepatitis B infection in Iran: a review article. J Res Med Sci. 2009;14(4):249-58.

4. Habibzadeh S, Davarnia B, Bazazataei A, Bagherzadeh S, Hamid Kholgh GR. Epidemiological evaluation of transfusion transmitted diseases in Ardabil in Tasoua and Ashoura 1381 (2003). Sci J Iran Blood Transfus Organ. 2004;1(2):55-60.

5. Pungpapong S, Kim WR, Poterucha JJ. Natural history of hepatitis B virus infection: an update for clinicians. Mayo Clin Proc. 2007;82(8):967-75. 
6. Chu CJ, Hussain M, Lok AS. Quantitative serum HBV DNA levels during different stages of chronic hepatitis B infection. Hepatology. 2002;36(6):1408-15.

7. Hadziyannis SJ, Lieberman HM, Karvountzis GG, Shafritz DA. Analysis of liver disease, nuclear HBcAg, viral replication, and hepatitis B virus DNA in liver and serum of HBeAg Vs. anti-HBe positive carriers of hepatitis B virus. Hepatology.1983;3(5):656-62.

8. de Franchis R, Hadengue A, Lau G, Lavanchy D, Lok A, McIntyre $\mathrm{N}$, et al. EASL International Consensus Conference on Hepatitis B. 13-14 September, 2002 Geneva, Switzerland. Consensus statement (long version). J Hepatol. 2003;39 Suppl 1:S3-25.

9. Brunt EM. Grading and staging the histopathological lesions of chronic hepatitis: the Knodell histology activity index and beyond. Hepatology. 2000;31(1):241-6.

10. Babamahmoodi F, Farokhee M, Delavarian L, Babamahmoodi A Khalilian A, Haghshenas MR. Association between Serum Concentrations of HBV-DNA and HBeAg with Liver Enzymes in Hepatitis B Patients. J Mazandaran Univ Med Sci.;22(95):2-8.

11. Semnani S, Besharat S, Jabbari A, Azarhoosh R, Keshtkar A, Rabiei MR, et al. The relationship between serum levels of hepatic transaminase with histopathological features in patients with chronic Hepatitis B. Horizon Med Sci. 2006;12(3):17-22.

12. Mommeja-Marin H, Mondou E, Blum MR, Rousseau F. Serum HBV DNA as a marker of efficacy during therapy for chronic HBV infection: analysis and review of the literature. Hepatology. 2003;37(6):1309-19.

13. Lindh M, Horal P, Dhillon AP, Norkrans G. Hepatitis B virus DNA levels, precore mutations, genotypes and histological activity in chronic hepatitis B. J Viral Hepat. 2000;7(4):258-67.

14. Fattovich G, Olivari N, Pasino M, D'Onofrio M, Martone E, Donato F. Long-term outcome of chronic hepatitis B in Caucasian patients: mortality after 25 years. Gut. 2008;57(1):84-90.

15. Gui HL, Wang H, Yang YH, Wu YW, Zhou HJ, Guo SM, et al. Sig nificant histopathology in Chinese chronic hepatitis B patients with persistently high-normal alanine aminotransferase. J Viral Hepat,;17 Suppl 1:44-50.

16. Kumar M, Sarin SK, Hissar S, Pande C, Sakhuja P, Sharma BC, et al. Virologic and histologic features of chronic hepatitis B virusinfected asymptomatic patients with persistently normal ALT. Gastroenterology. 2008;134(5):1376-84. 